\title{
Characterization of the Parameters of Interior Permanent Magnet Synchronous Motors for a Loss Model Algorithm
}

\author{
M. Caruso, A. O. Di Tommaso, R. Miceli, C. Nevoloso, C. Spataro, F. Viola \\ Department of Energy, Information Engineering and Mathematical Models, University of \\ Palermo, Viale delle Scienze, Building n.9, 90128 Palermo (Italy), ciro.spataro@unipa.it
}

\begin{abstract}
The paper provides the results of a detailed experimental study on the variations of the characteristics of an interior permanent magnet synchronous motor, when load, speed and/or magnetization conditions vary. In particular, the characterization is carried out by assessing, for several working conditions, the motor parameters that influence its efficiency. From the knowledge of the variability of these parameters, it is possible to develop a dynamic model of the motor, which accurately describes its behaviour and allows estimating the power losses for whatever speed and load. In order to validate the model, the values of the power losses obtained by using the model are compared with the values measured with experimental tests.

The study shows that it is possible to maximize the motor efficiency just acting on the direct axis current component and, therefore, it can be considered a first step towards the definition of a loss model algorithm for a control drive system able to minimize in real-time the power losses of the motor.
\end{abstract}

Keywords - interior permanent magnet synchronous motors, power loss minimization, speed control drive systems.

\section{INTRODUCTION}

The interior permanent magnet synchronous motors (IPMSMs) are more and more employed in several low/medium power industrial drive applications. Their wide spread is due to their better performances with respect to the traditional synchronous and asynchronous motors; in particular the IPMSMs have higher power factor, higher torque/weight ratio and higher power/current ratio. Furthermore, the increasing adoption of IPMSMs for several industrial applications over the last decades has been also supported by the achievement of innovative control algorithms.

A relevant branch of these strategies is represented by the Loss Model Algorithms (LMAs), which consider the power losses minimization of the motor by choosing the appropriate level of magnetization in order to maximize its efficiency for different working conditions. The most diffused losses minimization approaches presented in the literature [1-7] can be classified in two main categories: the Search Control (SC) and the Loss Model Control (LMC).

The first strategy consists of a step-by-step change of a control variable and a real-time measurement of the active power of the motor. More in particular, for every change of the control variable, the active power of the motor is measured and compared with the value corresponding to the previous iterative step. This technique does not require either the knowledge of the model or the values of the machine parameters. However, the torque pulsation generated by the step-by-step change of the control variable can be a significant disadvantage for the SC technique. Some examples are reported in [8-11]. On the contrary, the LMC strategy is based on the development of mathematical and circuital models that estimate the energy losses during the operation of the motor. This technique acts on the control quantities as current or magnetization level of the machine in order to estimate the working point 
corresponding to the minimum value of the power losses for a specified working condition. This fast and simple strategy is not subjected to torque pulsation, even though it requires a very accurate model for the identification of the minimum power losses conditions. In [12], the authors adopt a LMA that operates in an iterative manner for the determination of the minimum power losses working condition. In [8] the value of the direct-axis current component $\left(i_{d}\right)$ that minimizes the power losses is determined analytically. In particular, by adopting polynomial equations, the $i_{d}$ component is determined as function of the quadrature-axis current component $\left(i_{q}\right)$ and some coefficients that are related with the angular speed of the motor. The work reported in [13] describes a loss model control algorithm, which uses an $i_{d}$ value derived from experimental measurements of the power losses of the motor. In [14] a LMA method, that combines the SC and the LMC approaches, is described. The work described in [15] considers also the power losses related to the converter that drives the motor and develops a comparison between the different typologies of LMAs. In this context, the non-linear phenomena involved during the working operation of the machine, such as the magnetic saturation and the thermal aspects, should be taken into account for an even more accurate identification of the minimum power losses condition. In [16] and [17], it is experimentally demonstrated that both the direct-axis and quadrature-axis inductances are function of the $i_{d}$ and $i_{q}$ currents, respectively. Reference [18] considers the variation of the iron losses as function of the electrical pulsation. However, among the previously described scenario, most of the algorithms discussed in literature do not take into account all of the possible variations of the parameters of the IPMSM model [19] and a complete experimental analysis that considers simultaneously all the parameter variations of the motor has not been described yet in the scientific literature.

For this purpose, this paper presents an experimental characterization of an IPMSM finalized to build an accurate dynamic model of the motor, which allows estimating the power losses for whatever speed and load, taking into account also the variations of all the motor parameters that influence its efficiency. More in detail, the loss model algorithm presented in [12] (here named LMA1) is compared with its new version, here named LMA2. To perform the task, we carried out a series of experiments, measuring, for several working settings, the motor parameters that have an impact on its power losses. In a second stage, we directly measured the power losses varying load, speed and magnetization conditions. The comparison of the results of these measurements with the values of the power losses obtained by using the models was used to validate the proposed approach.

\section{DESCRIPTION OF THE LOSS MINIMIZATION ALGORITHM}

The starting point of our study is a well-known IPMSM model presented in several literature studies as a "circuital approach" [20-24].

The dynamic model is based on the hypothesis of linearity and isotropy of the magnetic material (stator and rotor iron), sinusoidal distribution of the magneto-motive force in the air gap and negligible eddy currents.
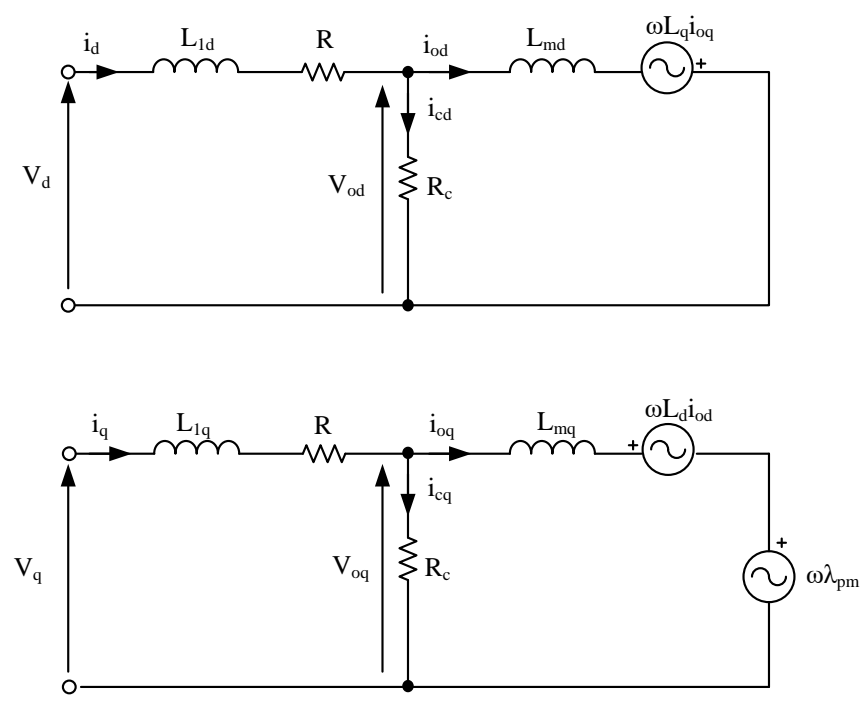

Fig.1 Dynamic d-q axes equivalent circuits of a IPMSM

By considering the two-axis theory of Park, the dynamic $d$ and $q$ axes equivalent circuits of the IPMSM can be drawn as shown in
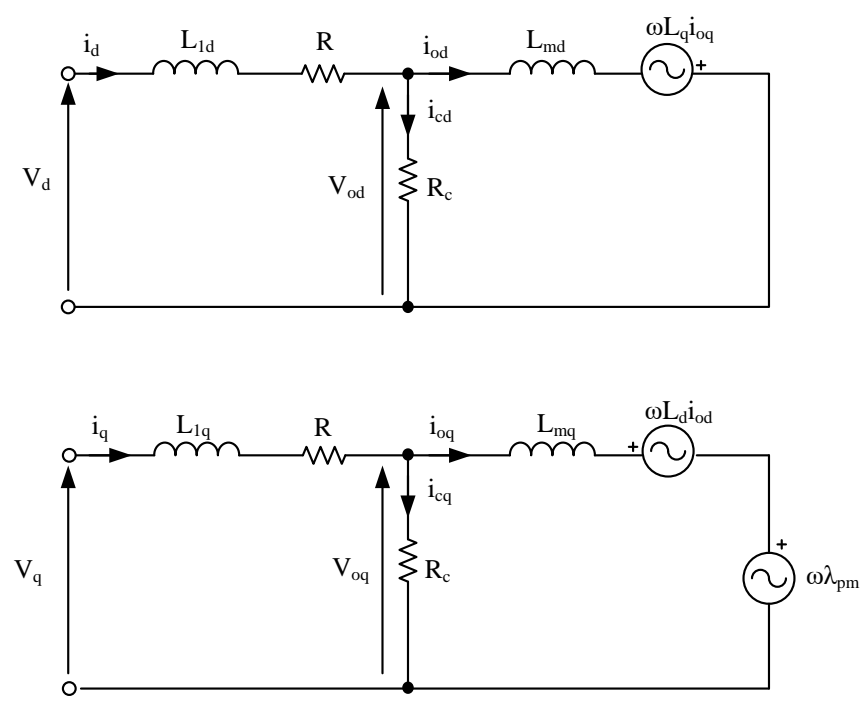

Fig.. The IPMSM mathematical dynamic model is:

$$
\begin{aligned}
& \frac{d i_{d}}{d t}=\frac{1}{L_{l d}}\left(v_{d}-R i_{d}-L_{m d} \frac{d i_{o d}}{d t}+L_{q} p \omega_{m} i_{o q}\right) \\
& \frac{d i_{q}}{d t}=\frac{1}{L_{1 q}}\left(v_{q}-R i_{q}-L_{m q} \frac{d i_{o q}}{d t}-L_{d} p \omega_{m} i_{o d}+p \omega_{m} \psi_{P M}\right)
\end{aligned}
$$


$\frac{d \omega_{m}}{d t}=\frac{1}{J}\left[T_{e}-F \omega_{m}-T_{m}\right]$

$\frac{d \vartheta_{m}}{d t}=\omega_{m}=\frac{\omega}{p}$

$T_{e}=\frac{3}{2} p\left[\psi_{P M} i_{o q}+\left(L_{m d}-L_{m q}\right) i_{o d} i_{o q}\right]$

$i_{o d}=i_{d}-i_{c d}$

$i_{o q}=i_{q}-i_{c q}$

$i_{c d}=\frac{-p \omega_{m} L_{q} i_{o q}+L_{m d} \frac{d i_{o q}}{d t}}{R_{C}}$

$i_{c q}=\frac{p \omega_{m}\left(\psi_{P M}+L_{d} i_{o d}\right)+L_{m q} \frac{d i_{o q}}{d t}}{R_{C}}$

where:

- $\quad v_{d}$ and $v_{q}$ are the direct and quadrature axes components of the stator phase voltages;

- $i_{d}$ and $i_{q}$ are the direct and quadrature axes components of the stator phase currents;

- $\quad i_{c d}$ and $i_{c q}$ are the direct and quadrature iron loss current components;

- $\quad i_{o d}$ and $i_{o q}$ are the direct and quadrature torque current components;

- $\quad p$ is the number of pole pairs;

- $\theta_{m}$ is the rotor mechanical angular position;

- $\omega_{m}$ is the rotor mechanical angular speed;

- $\omega$ is the electrical angular speed;

- $\psi_{P M}$ is the flux generated by the permanent magnets;

- $R$ is the resistance of the three-phase stator winding;

- $R_{C}$ is the resistance that symbolizes the iron losses;

- $\quad L_{d}$ and $L_{q}$ are the direct and quadrature axes inductances;

- $\quad L_{l d}$ and $L_{l q}$ are the direct and quadrature-axes leakage inductances;

- $\quad L_{m d}$ and $L_{m q}$ are the direct and quadrature-axes magnetizing inductances;

- $T_{e}$ is the electromagnetic torque;

- $T_{m}$ is the load torque;

- $F$ is the coefficient of viscous friction;

- $J$ is the moment of inertia of the rotating parts.

From these equations, it is possible to calculate the power losses $\Delta P_{t o t}$, composed (for a IPMSM) by the sum of:

- $\quad$ the losses in the stator and rotor iron $\left(\Delta P_{f e}\right)$;

- the joule losses in the stator winding $\left(\Delta P_{c u}\right)$;

- the mechanical losses for friction and ventilation $\left(\Delta P_{m}\right)$;
- $\quad$ the additional losses $\left(\Delta P_{a d d}\right)$.

These losses can be divided in controllable and uncontrollable losses. The copper and iron losses, determined by the stator current and by the total linkage flux, respectively, are controllable.

Contrariwise, the mechanical losses are uncontrollable since they depend only on the motor angular speed. In this framework, the additional losses (a very low percentage of the total losses) are neglected.

In a steady-state-condition, it is possible to find mathematical expressions of the copper losses and iron losses by combining the equations (1), (2), (6), (7), (8) and (9).

$\Delta P_{c u}=\frac{3}{2} R\left(i_{d}^{2}+i_{q}^{2}\right)=$

$=\frac{3}{2} R\left\{\left(i_{o d}-\frac{p \omega_{m} L_{q} i_{o q}}{R_{c}}\right)^{2}+\left(i_{o q}+\frac{p \omega_{m}\left(\psi_{P M}+L_{d} i_{o d}\right)}{R_{c}}\right)^{2}\right\}$

$\Delta P_{f e}=\frac{3}{2} R_{c}\left(i_{c d}^{2}+i_{c q}^{2}\right)=$

$=\frac{3}{2} \frac{p^{2} \omega_{m}^{2}}{R_{c}}\left[\left(L_{q} i_{o q}\right)^{2}+\left(\psi_{P M}+L_{d} i_{o d}\right)^{2}\right]$

Therefore, the total controllable losses are a function of $\omega_{m}, i_{o d}, i_{o q}, L_{d}, L_{q}, \psi_{P M}, R$ and $R_{C}$. The last five elements are not adjustable parameters and, for a stated motor working condition (namely load and speed), neither $\omega_{m}$ or $i_{o q}$ can be used to control the motor losses. Therefore, the motor efficiency can be controlled only by acting on the $i_{o d}$ value, but, since for a stated motor working condition the $i_{c d}$ value is constant, the power losses can be controlled by directly adjusting the direct-axis current $i_{d}$.

In order to carry out an accurate estimation of the minimum losses point, it is necessary to take into account the variation of the motor parameters that influence its efficiency. In particular, the direct and quadrature axis inductances and the flux of the rotor magnets depend on the magnetic saturation, mainly in the motors with little air-gap and high magnetic flux $[14,17,25]$. The variation of these parameters is generated by the armature reaction and, therefore, its effect is bigger for high value of angular speed and load.

As regards the armature resistance $R$, which depends on its temperature, it is possible to neglect its variability, if we consider the stator in a thermal steady state.

We took into account also the variability of the resistance $R_{C}$, which depends on the rotor speed.

\section{TEST BENCH}

In order to achieve the goals described in the previous sections, an experimental test bench has been set up. A schematic representation of the proposed test bench is shown in Errore. L'origine riferimento non è stata trovata.. 


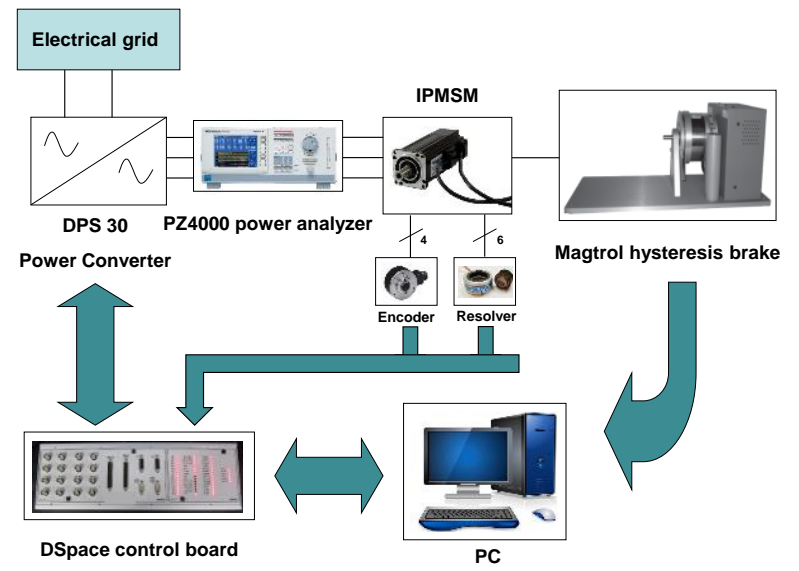

Fig. 2 Schematic representation of the test bench

More in detail, the bench (see Fig. 3) is composed of:

- a three-phase, six-pole brushless machine (Magnetic S.r.l., type BLQ-40), with SmCo permanent magnets (HITACHI Inc., type H-18B, with maximum specific energy equal to $143 \mathrm{~kJ} / \mathrm{m}^{3}$ ) (Errore. L'origine riferimento non è stata trovata.). The stator winding is a three-phase, double-layer, shortened pitch, located into 27 slots. Table 1 reports the main rated values and parameters of the machine under test;

- a DPS 30 A power converter (Automotion Inc.), directly connected to the electrical grid;

- a dSPACE $®$ rapid prototyping control board, in order to drive the IGBT bridge of the converter. Furthermore, two current sensors are integrated into the electronic power converter module and their output signals are sent to the dSPACE® board;

- a HD-715 hysteresis brake (Magtrol Inc.), which allows to perform experimental tests at different load conditions

- a DSP6001 high-speed programmable dynamometer controller (Magtrol Inc.), used to drive the brake;

- a PZ 4000 three-phase power analyzer (Yokogawa Inc), used to measure the electrical quantities in the various working conditions of the motor;

- an ARTUS resolver (type 26SM19 U452), which is connected to the motor shaft in order to measure the motor speed;

- a variable auto-transformer (Variac Inc.), used for the measurement of the stator winding parameters;

- a PC with the dSPACE®-based electrical drive user interface, which allows to perform the real-time control and the supervision of the main electrical and mechanical quantities of the proposed system.
Table 1. Rated values and parameters of the IPMSM under test

\begin{tabular}{|l|l|}
\hline Voltage & $132 \mathrm{~V}$ \\
\hline Current & $3.6 \mathrm{~A}$ \\
\hline Speed & $4000 \mathrm{rpm}$ \\
\hline Torque & $1.8 \mathrm{~N} \cdot \mathrm{m}$ \\
\hline Number of pole pairs & 3 \\
\hline Average stator resistance $R$ & $2.21 \Omega$ \\
\hline Direct-axis inductance $L_{d}$ & $7.50 \mathrm{mH}$ \\
\hline Quadrature-axis inductance $L_{q}$ & $11.00 \mathrm{mH}$ \\
\hline PMs flux $\Psi_{P M}$ & $0.084 \mathrm{~Wb}$ \\
\hline Coefficient of viscous friction $F$ & $0.001 \mathrm{~N} \cdot \mathrm{m} \cdot \mathrm{s}$ \\
\hline Inertia moment $J$ & $0.001 \mathrm{~kg} \cdot \mathrm{m}^{2}$ \\
\hline &
\end{tabular}

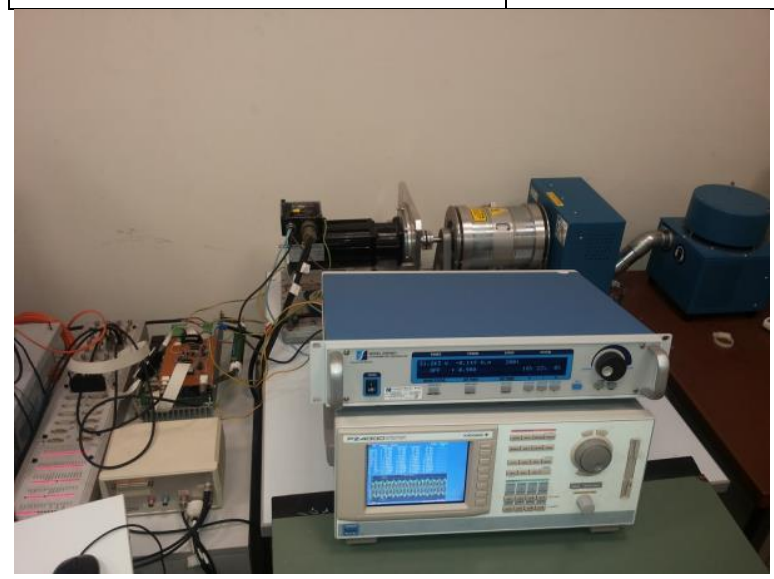

Fig. 3 The test bench

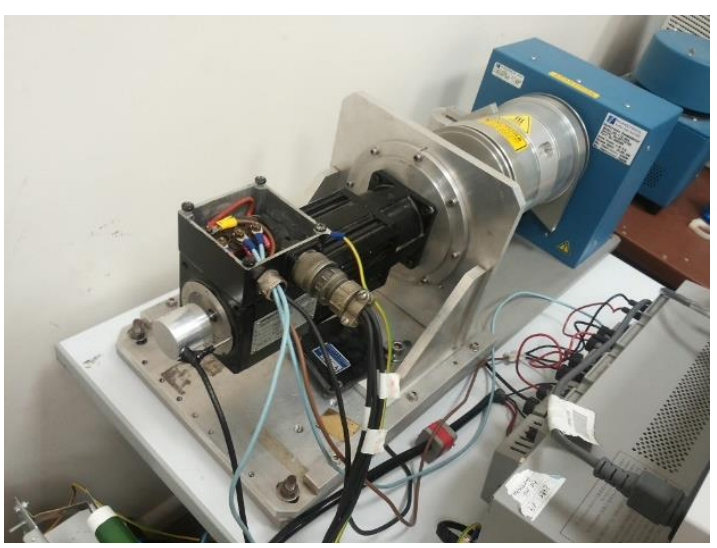

Fig. 4 The IPMSM under test

\section{MESAUREMENT OF THE MOTOR PARAMETERS}

The direct and quadrature axis inductances were evaluated by means of blocked rotor tests. We measured the $L_{d}$ for various $i_{d}$ values, blocking the rotor at the $0^{\circ}$ position, and 
the $L_{q}$ for various $i_{q}$ values, blocking the rotor at the $90^{\circ}$ electrical position. Fig. shows how the stator windings are connected to the measurement system.

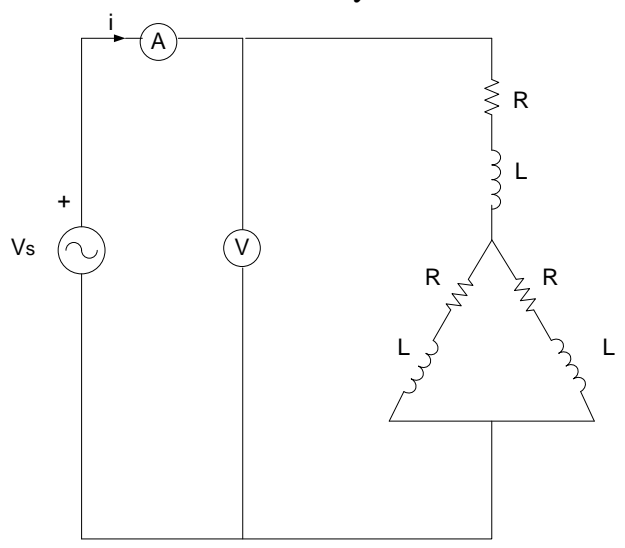

Fig. 5 Schematic for the measurement of $L_{d}$ and $L_{q}$

The $L$ values were calculated starting from the measured values of $Z$ and $R$ as:

$L=\frac{2}{3} \frac{\sqrt{Z^{2}-R^{2}}}{2 \pi f}$

In Fig. and in Fig. , the direct and quadrature axis inductances, as functions of $i_{d}$ and $i_{q}$ respectively, are reported. The expanded uncertainty $(k=2)$ of the inductance measurements is $1.4 \%$ [28]. It is possible to notice that the maximum $L_{d}$ value is $33 \%$ higher than the minimum $L_{d}$ value and that the maximum $L_{q}$ value is $12 \%$ higher than the minimum $L_{q}$ value.

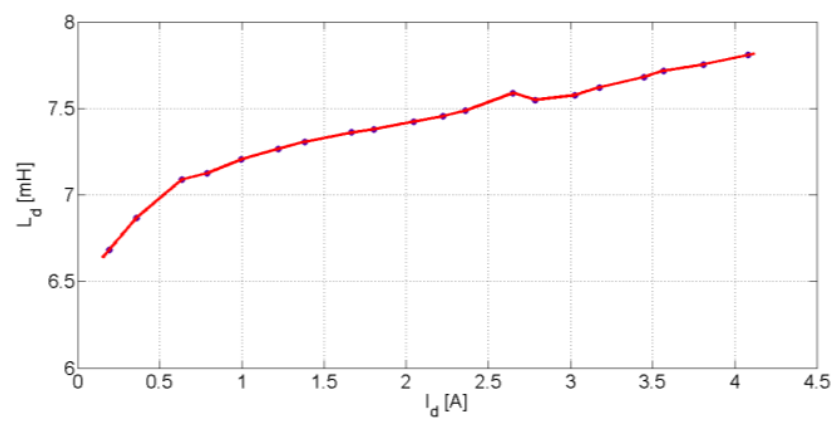

Fig. 6 Direct axis inductance as a function of $i_{d}$

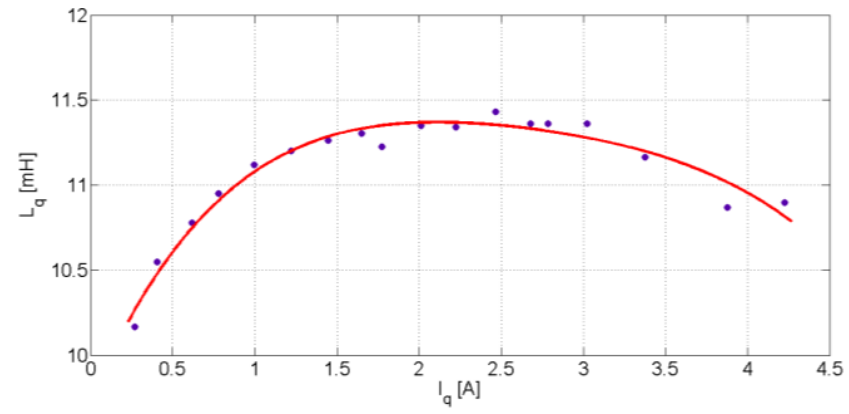

Fig. 7 Quadrature axis inductance as a function of $i_{q}$

In order to evaluate the magnetic flux variability, we performed other blocked rotor tests, fixing the rotor position at the $90^{\circ}$ electrical position and, therefore, setting $i_{d}=0$. The torque $T_{m}$ was measured by means of the dynamometer for various $i_{q}$ values. Starting from Eq. (5), the flux value is given by:

$\psi_{p m}=\frac{2}{3} \frac{T_{m}}{p i_{q}}$

The Fig. reports the magnetic flux trend versus $i_{q}$. The expanded uncertainty $(k=2)$ of the flux measurements is $2 \%$. In this case, the maximum $\psi_{P M}$ value is $3.5 \%$ higher than the minimum $\psi_{P M}$ value.

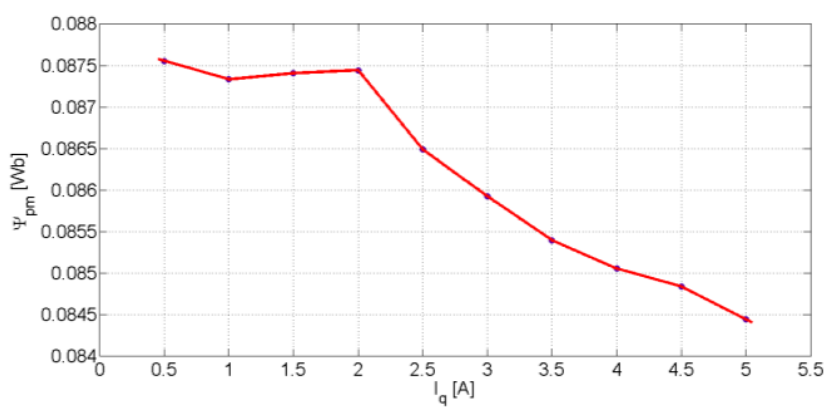

Fig. 8 Magnetic flux as a function of $i_{q}$

The assessment of the resistance $R_{C}$ representing the iron losses was carried out by means of no-load tests, for various motor speeds. In these conditions, the motor power consumption $P_{\text {in }}$ is:

$P_{\text {in }}=\Delta P_{f e}+\Delta P_{c u}+\Delta P_{m}$

$\Delta P_{c u}$ are calculated as $3 R I$ where $I$ is the current of each stator winding; $\Delta P_{m}$ are evaluated by means of a deceleration test. Therefore, by measuring the motor input electric power and rearranging the Eq. (15), it is possible to calculate the iron losses for various motor speeds. The values of the resistance $R_{C}$ representing the iron losses were obtained from Eq. (16):

$R_{C}=\frac{V^{2}}{\Delta P_{f e}}$

The Fig. shows the $R_{C}$ trend as a function of the rotor speed $\omega_{\mathrm{m}}$. 


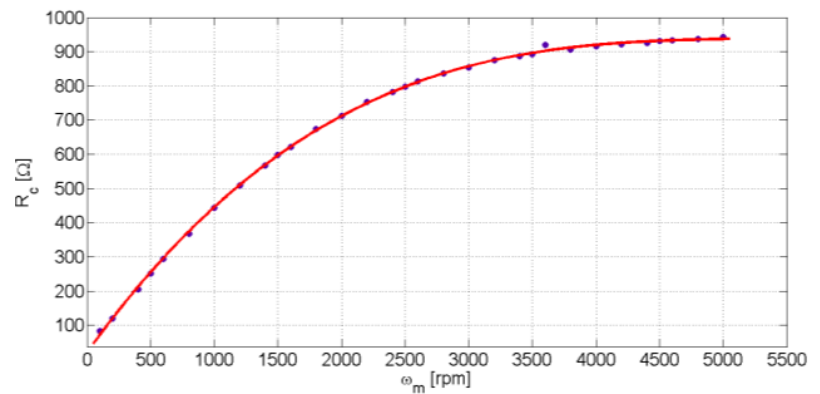

Fig. $9 R_{C}$ as a function of the rotor speed

Considering the variability of these four parameters and by means of the dynamic model of the motor, it is possible to evaluate the power losses for whatever speed and load.

\section{TESTS FOR THE DIRECT MEASUREMENT OF THE MOTOR LOSSES}

With the same test bench described in Section III, several experimental tests were carried out in order to determine the value of the direct-axis current component corresponding to the minimum value of power losses for different working conditions and to validate the proposed approach. More in detail, the motor was driven with a reference speed ranging from 500 to $4000 \mathrm{rpm}$, with steps of $500 \mathrm{rpm}$, obtaining eight different speed tests. In addition, for each speed, a variable load was applied to the motor, from $0 \%$ (no load condition) to $100 \%$ (full load condition) with steps of $25 \%$, obtaining 40 overall working conditions with defined speed and load. Moreover, for each working conditions, a specified IPMSM magnetization level was set by acting on the value of the direct-axis current of the control system. In particular, the $i_{d}$ value was varied from $-2.4 \mathrm{~A}$ to $+2.4 \mathrm{~A}$ with steps of $0.2 \mathrm{~A}$. Therefore, for each working conditions, 25 different magnetization conditions were achieved. All things considered, we assessed the minimum losses point for 1000 different overall working conditions [26-27], measuring the power losses as difference between the electrical input power and the mechanical output power [21-22]. The expanded uncertainty $(\mathrm{k}=2)$ of the $\Delta P_{t o t}$ measurements is $2 \mathrm{~W}$.

In order to justify the hypothesis of a thermal steady state and guarantee a roughly constant stator winding temperature, all the $\Delta P_{\text {tot }}$ measurements were carried out in the following way. We let the motor work at the full speed and load until its external temperature reached the thermal equilibrium $\left(65.0{ }^{\circ} \mathrm{C}\right)$. Then, after selecting the various speeds and loads, we carried out the measurements in 2 minutes, before the motor temperature drops below $64.0{ }^{\circ} \mathrm{C}$.

For instance, the $\Delta P_{\text {tot }}$ characteristics as a function of $i_{d}$ at no load conditions at $500 \mathrm{rpm}$ are reported in Fig. . As it is possible to notice, the minimum value of power losses is obtained for a negative value of the $i_{d}$ current. By changing the applied load, the minimum value of $\Delta P_{\text {tot }}$ slides through higher negative values of the direct-axis current.

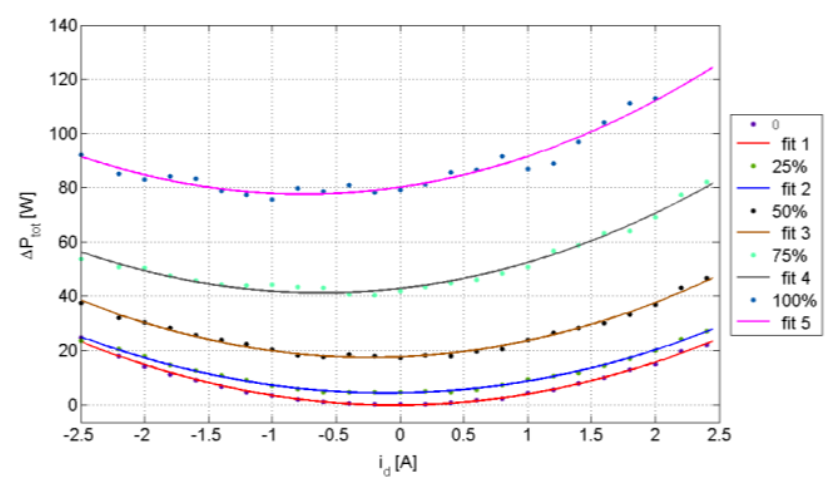

Fig. 10 Losses vs $i_{d}$ for various load conditions at $500 \mathrm{rpm}$

Fig. shows the $\Delta P_{\text {tot }}$ vs $i_{d}$ characteristics parametrized as function of the reference speed at no load. As expected, the minimum values of power losses are obtained for negative values of $i_{d}$. In addition, by increasing the applied load, the related peaks are detected for higher negative values of $i_{d}$. In any case, for each operating condition of the motor, it is always possible to determine a specified $i_{d}$ value that maximizes the IPMSM efficiency without decreasing the dynamic performances of the drive.

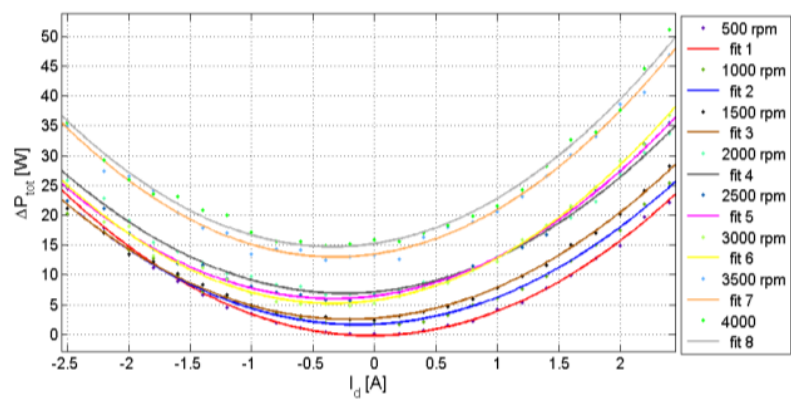

Fig. 11 Losses vs id for different speed conditions at no load

In order to validate the proposed LMAs, the experimental results obtained from the previous tests were compared with those achieved with the two loss model algorithms. As examples, Fig. and Fig. show this comparison at no load and for a reference speed respectively equal to 1500 and $3000 \mathrm{rpm}$, respectively. It can be noticed that the algorithm that takes into account the parameter variations is more accurate in terms of power losses estimation. 


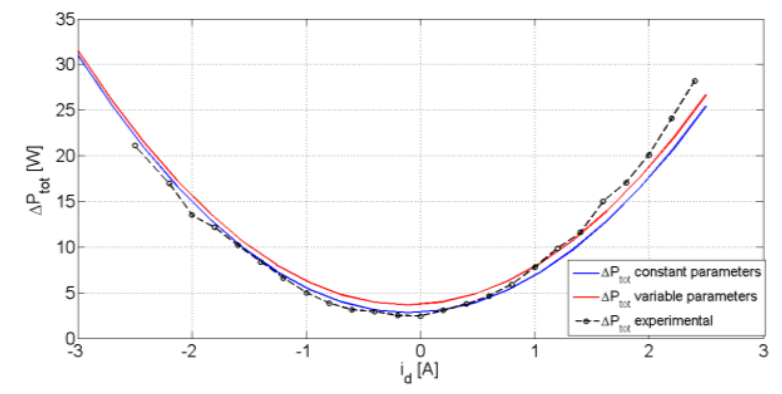

Fig. 12 Comparison between the losses evaluated with the model and the measured losses (1500 rpm; no-load)

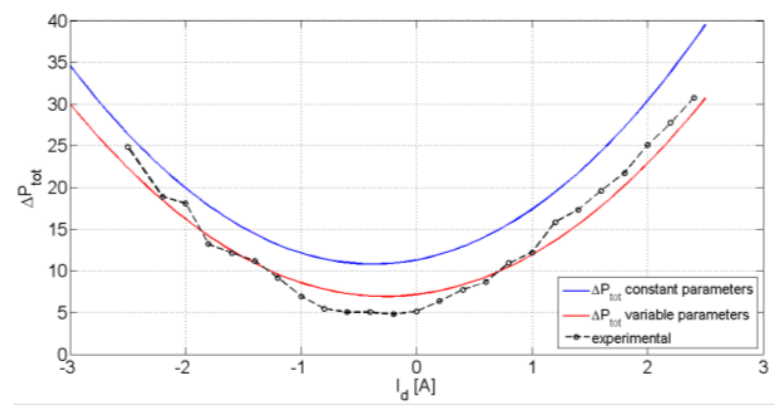

Fig. 13 Comparison between the losses evaluated with the model and the measured losses (3000 rpm; no-load)

Similar results are obtained when a load is applied, as shown in Fig. 1, which reports the comparison between the estimated losses and the measured ones at $1500 \mathrm{rpm}$ and for an applied load equal to $25 \%$. As well as for the previous case, the detection of $\Delta P_{t o t}$ is more accurate for the LMA2. As could be expected, the differences between the two models increase, as the motor speed and/or load increase.

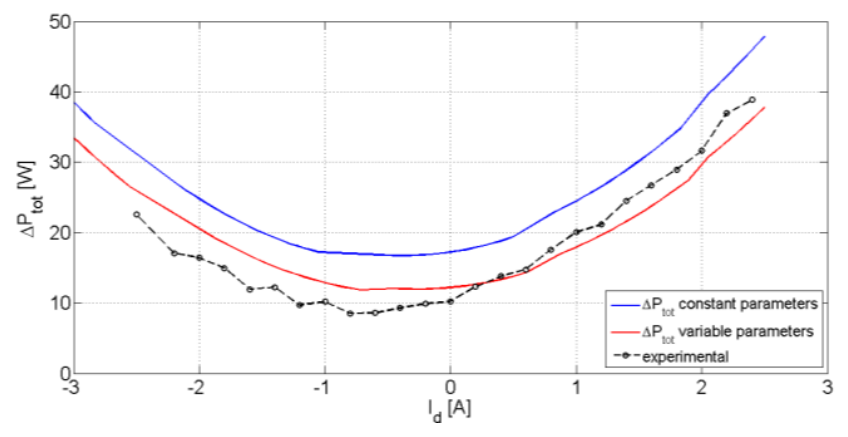

Fig. 1 Comparison between the losses evaluated with the model and the measured losses (3000 rpm; $25 \%$ load)

In all considered cases, taking into account the variability of the motor parameters leads to a more accurate assessment of the motor losses rather than using a model with constant parameters. These results validate both the proposed model and the accuracy on the measurement of the parameters.

For the specific motor under test, the advantage of the LMA2 usage for the estimation of the minimum losses point is only in terms of $\Delta P_{t o t}$, while in terms of $i_{d}$ values (for which the condition of minimum power losses is obtained) the LMA1 practically detects the same values. Moreover, since around the minimum losses point the derivative of $\Delta P_{t o t}$ is quite small, even a not accurate assessment of the minimum losses point abscissa allows a good optimization of the motor efficiency.

Even if, in this contest, we considered the motor in a thermal steady state and, therefore, we did not take into account the variability of the armature resistance $R$, it is obvious that this condition can seldom be considered true, mainly when load and/or speed of the motor change continuously. In order to take into account also the variability of the armature resistance, it would be necessary to measure the stator internal temperature making the control system more expensive. However, also in this case, considering the variability of the $R$ is again an advantage only in terms of $\Delta P_{t o t}$ and not in terms of $i_{d}$.

Therefore, it can be stated that considering the variability of the motor parameters is worthwhile only when it is necessary to measure the power losses, whereas it is not so significant to find the magnetization condition that guarantees the minimum power losses.

In order to verify how the model is sensitive to the values of the aforementioned parameters, we carried out a onefactor-at-a-time sensitivity analysis. The results of this investigation show that the model is practically insensitive to the variation of $L_{d}, L_{q}$ and $R_{C}$, whereas it is very sensitive to the variation of $\psi_{P M}$ and $R$. Therefore, to achieve an accurate estimate of the losses, it is necessary an accurate measurement of the flux generated by the magnets and of the armature resistance. On the contrary, the values of the other parameters can be assessed in an approximated way, without jeopardizing the estimate of the motor losses.

\section{CONCLUSIONS}

In the scientific literature, various authors presented different control strategies aimed to increase the efficiency of the interior permanent magnet synchronous motors. These strategies, starting from a well-known mathematical model of the dynamic behaviour of the motor, are able to reduce the power losses acting on the magnetizing component of the stator current.

However, the proposed approaches do not take into account that, varying the working conditions of the motor, also the values of the parameters, which have an impact on the power losses, can vary.

In this paper, therefore, starting from an accurate measurement of the motor characteristics for various values of speed and load, we presented a new control strategy, which, by taking into account the variability of the motor parameters, allows to sharp the dynamic model and to obtain a more accurate estimate of the power losses of the motor.

The validity of the model was verified by comparing the power loss estimates with the loss values obtained from 
experimental tests, directly measuring the power losses as difference between the electrical input power and the mechanical output power. The results of the study demonstrate that the proposed loss model algorithm allows a more accurate detection of the minimum losses point. However, for the particular tested motor, the accuracy improvement is only in terms of $\Delta P_{t o t}$ and not in terms of $i_{d}$ values. Therefore, measuring and taking into account the variability of the motor parameters is meaningful only to measure the power losses, but it is not useful to find the $i_{d}$ value that, for a stated working condition of the motor, assures the maximum motor efficiency.

Because of its high flexibility, the proposed approach is applicable to several typologies of brushless motors and their related applications.

\section{ACKNOWLEDGEMENTS}

This work was realized with SDESLab - University of Palermo and with the funding of the project "Mediterranean network for emerging nanomaterials MedNETNA" (CUP:E61J12000100006).

\section{REFERENCES}

[1] S. Vaez, V. John, and M. Rahman, "Adaptive loss minimization control of inverter-fed ipm motor drives," in Power Electronics Specialists Conference, 1997. PESC '97 Record., 28th Annual IEEE, vol. 2, pp. 861-868 vol.2, Jun 1997.

[2] C. Mademlis, J. Xypteras, and N. Margaris, "Loss minimization in surface permanent-magnet synchronous motor drives," Industrial Electronics, IEEE Transactions on, vol. 47, pp. 115-122, Feb 2000.

[3] F. Fernandez-Bernal, A. Garcia-Cerrada, and R. Faure, "Model-based loss minimization for dc and ac vector controlled motors including core saturation," in Industry Applications Conference, 1999. ThirtyFourth IAS Annual Meeting. Conference Record of the 1999 IEEE, vol. 3, pp. 1608-1615 vol.3, 1999.

[4] A. Bazzi and P. Krein, "Review of methods for realtime loss minimization in induction machines," Industry Applications, IEEE Transactions on, vol. 46, pp. 2319-2328, Nov 2010.

[5] F. Azevedo and M. Uddin, "Recent advances in loss minimization algorithms for ipmsm drives," in Industry Applications Society Annual Meeting, 2014 IEEE, pp. 1-9, Oct 2014.

[6] A.O. Di Tommaso, R. Miceli, G.R. Galluzzo, and M. Trapanese, "Optimum performance of permanent magnet synchronous generators coupled to wind turbines"in 2007 IEEE Power Engineering Society General Meeting, PES

[7] A.O. Di Tommaso, R. Miceli, G.R. Galluzzo, and M. Trapanese, "Efficiency control for permanent magnet synchronous generators" in Proceedings of the IEEE International Conference on Industrial Technology, art. no. 4237887, pp. 2079-2084.

[8] C.Mademlis, I. Kioskeridis and N. Margaris, "Optimal efficiency control strategy for interior permanent-magnet synchronous motor drives," in IEEE Transactions on Energy Conversion, vol. 19, no. 4, pp. 715-723, Dec. 2004.
[9] S. Vaez, V. I. John and M. A. Rahman, "An on-line loss minimization controller for interior permanent magnet motor drives," in IEEE Transactions on Energy Conversion, vol. 14, no. 4, pp. 1435-1440, Dec 1999.

[10] S. Vaez, V. I. John and M. A. Rahman, "Adaptive loss minimization control of inverter-fed IPM motor drives," PESC97. Record 28th Annual IEEE Power Electronics Specialists Conference. Formerly Power Conditioning Specialists Conference 1970-71. Power Processing and Electronic Specialists Conference 1972, St. Louis, MO, 1997, pp. 861-868 vol.2.

[11] C. Mademlis, J. Xypteras and N. Margaris, "Loss minimization in surface permanent-magnet synchronous motor drives," in IEEE Transactions on Industrial Electronics, vol. 47, no. 1, pp. 115-122, Feb 2000.

[12] C. Cavallaro, A. O. Di Tommaso, R. Miceli, A. Raciti, G. R. Galluzzo and M. Trapanese, "Efficiency Enhancement of Permanent-Magnet Synchronous Motor Drives by Online Loss Minimization Approaches," in IEEE Transactions on Industrial Electronics, vol. 52, no. 4, pp. 1153-1160, Aug. 2005.

[13] J. Lee, K. Nam, S. Choi e S. Kwon, "A Lookup Table Based Loss Minimizing Control for FCEV Permanent Magnet Synchronous Motors", in IEEE Vehicle Power and Propulsion Conference, Arlington, TX,pp. 175-179, 2007.

[14] K. Yu, H. Guo e Z. Sun, Efficiency Optimization Control of Permanent Magnet Synchronous Motor for Electric Propulsion System, Busan, Korea: 2013 International Conference on Electrical Machines and Systems, Oct. 26-29, 2013.

[15] C. Mademlis and N. Margaris, "Loss minimization in vector-controlled interior permanent-magnet synchronous motor drives," in IEEE Transactions on Industrial Electronics, vol. 49, no. 6, pp. 1344-1347, Dec 2002.

[16] C. Mademlis e V. G. Agelidis, "On Considering Magnetic Saturation with Maximum Torque to Current Control in Interior Permanent Magnet Synchronous Motor Drives", IEEE Transactions on energy conversion, vol. 16, no. 3, September 2001.

[17] J. Lee, K. Nam e S. Choi, "Loss-Minimizing Control of PMSM With the Use of Polynomial Approximations", IEEE Transactions on power electronics, vol. 24, no. 4, April 2009.

[18] S. Vaez e J. Vilayil, "Minimum Loss Operation of PM Motor Drives", IEEE Canadian Conference on , vol.1, no., pp.284-287 vol.1, September 1995

[19]S. Morimoto, Y. Tong e Y. Takeda, "Loss Minimization Control of Permanent Magnet Synchronous Motor Drives", IEEE Transactions on industrial electronics, vol. 41, no. 5, October 1994.

[20] M. Fazil and K. R. Rajagopal, "Nonlinear dynamic modeling of a singlephase permanent-magnet brushless dc motor using 2-d static finiteelement results," Magnetics, IEEE Transactions on, vol. 47, pp. 781-786, April 2011.

[21]M. Hussin, M. Azuwir, and Y. N. Zaiazmin, "Modeling and validation of brushless dc motor," in Modeling, Simulation and Applied Optimization (ICMSAOO), 2011 4th International Conference on, pp. 1-4, April 2011.

[22] O. Mohammed, S. Liu, and Z. Liu, “A phase variable model of brushless dc motors based on finite element analysis and its coupling with external circuits," Magnetics, IEEE Transactions on, vol. 41, pp. 15761579, May 2005. 
[23]B. Kerdsup and N. Fuengwarodsakul, "Dynamic model of brushless dc drive using fe method based characteristics," in Power Electronics and Drive Systems (PEDS), 2011 IEEE Ninth International Conference on, pp. 66-71, Dec 2011.

[24] A. Matsumoto, M. Hasegawa, and S. Doki, "A novel ipmsm model for robust position sensorless control to magnetic saturation," in Power Electronics Conference (IPEC-Hiroshima 2014 - ECCE-ASIA), 2014 International, pp. 2445-2450, May 2014.

[25]Z. Li and H. Li, "MTPA control of PMSM system considering saturation and cross-coupling," Electrical Machines and Systems (ICEMS), 2012 15th International Conference on, Sapporo, 2012, pp. 1-5

[26] M. Caruso, A. O. Di Tommaso, F. Genduso and R. Miceli, "Experimental investigation on high efficiency real-time control algorithms for IPMSMs," Renewable Energy Research and Application (ICRERA), 2014 International Conference on, Milwaukee, WI, 2014, pp. 974-979.

[27] M. Caruso, A. O. Di Tommaso, R. Miceli and C. Spataro, "Experimental study on efficiency enhancement in Interior Permanent Magnet Synchronous machines," Clean Electrical Power (ICCEP), 2015 International Conference on, Taormina, 2015, pp. 518-522.

[28] C. Spataro, “ADC based measurements: A common basis for the uncertainty estimation" in Proceedings of 17th Symposium IMEKO TC 4, 3rd Symposium IMEKO TC 19 and 15th IWADC Workshop. p. 389393, Kosice, Slovak Rep.,, 8-10 Sept. 2010. 